\title{
Thermal Distortion Compensation for Improving Electrical Performance of Reflector Antennas
}

\author{
Jiamei Kang*, Wei Wang, Shuo Zhang, Shaofan Lian, Hong Bao \\ Key Laboratory of Electronic Equipment Structure Design, Ministry of Education, Xidian University, Xi'an, China \\ Email: ^2563097372@qq.com
}

How to cite this paper: Kang, J.M., Wang, W., Zhang, S., Lian, S.F. and Bao, H. (2021) Thermal Distortion Compensation for Improving Electrical Performance of Reflector Antennas. Open Journal of Applied Sciences, 11, 523-540.

https://doi.org/10.4236/ojapps.2021.114037

Received: March 4, 2021

Accepted: April 26, 2021

Published: April 29, 2021

Copyright $\odot 2021$ by author(s) and Scientific Research Publishing Inc. This work is licensed under the Creative Commons Attribution International License (CC BY 4.0).

http://creativecommons.org/licenses/by/4.0/

(c) (i) Open Access

\begin{abstract}
Aiming at the problem of the surface accuracy and electrical performance of the antenna in space environment are reduced due to thermal deformation caused by temperature load. This paper presents a method to compensate the thermally induced shape distortion of antenna reflector by actively adjusting actuators in order to improve the electrical performance. The adjustment of each actuator is related to the local deformation of the panel. Then, taking a space deployable antenna with a diameter of 5 meters as an example, the finite element model is established. According to the range of the temperature variation in space $\left(-180^{\circ} \mathrm{C}-200^{\circ} \mathrm{C}\right)$, different temperature loads are applied to the antenna. The variation of electrical properties and surface accuracy is analyzed and the worst working condition is determined, and the antenna is compensated based on this condition. Then, four different electrical performance parameters are used as the optimization objectives, and the electromechanical coupling optimization model is established, and the PSO algorithm is used to optimize the actuators adjustments. The results show that the method can effectively improve the electrical performance of the deformed reflector antenna.
\end{abstract}

\section{Keywords}

Space Reflector Antenna, Thermal Distortion, Active Compensation, Electrical Performance, PSO

\section{Introduction}

With the development of space science and technology, space reflector antennas have received tremendous attention. They are frequently used in satellite communication, radio astronomy, space exploration [1] [2] [3] [4] [5], etc. At the 
same time, the working environment is getting worse and more diversified, which requires higher surface precision and electrical performance. The space reflector antennas need to be deployed in the harsh thermal environment in earth's orbit and experience the wide temperature ranging from $-180^{\circ} \mathrm{C}$ to $+200^{\circ} \mathrm{C}$ [6]. The material of antenna is thermally deformed over wide temperature range. The thermally induced shape distortion of antenna affects the surface precision and electrical performance seriously. The electrical performance of the antenna is very rigorous on the surface accuracy and even small distortion in the structure can degrade the electrical performance [7]. So it is critical for the electrical performance of the antenna to maintain the surface accuracy.

In order to maintain the surface accuracy, the surface accuracy of antenna should be measured accurately. So the measurement of the surface accuracy of deployable reflector antenna is a significant issue. Different solutions available in the literature to solve this problem have been reviewed. Takashi Iwasa et al. adopted a high resolution surface shape measurement system which combines grating projection method and a virtual-target registration method to measure the surface shape [8]. Masashi Shimizu et al. proposed a method to evaluate the deformation of reflector by measuring the approach pattern of antenna [9]. Shufei Feng et al. proposed a worst-case surface accuracy evaluation method based on the EA adjustment strategy, which can enable further improvement of the worst-case surface accuracy [10].

Many scholars have studied the shape control of different types of reflector antennas. For the shape control of large flexible structures, such as the inflatable membrane reflector, much work has been done by several authors in the literature. C. H. Jenkins realized the shape control by using neural network strategy, which conducts control and/or learning in real time based only on the kinematic system information [11]. Another method for addressing this issue is using the co-gradient algorithm to optimize the space inflatable membrane reflector [12]. More recent works by establishing numerical model and random sensitivity analysis are used to study the shape error of antennas [13] [14] to reduce the error effectively.

Several methods for the shape control of cable net antennas have been reported. Ruiwei Liu et al. used a genetic algorithm to optimize the pretensions in the deployable structure [15] and proposed a parameter optimization genetic algorithm method based on the constrains of frequency to optimize the structure and parameters of cable-rib tension of expandable antenna [16]. Jingli Du et al. used the minimal norm least squares method to solve the problem of shape adjustment with modeling uncertainty [17] and used the model update to reduce the shape adjustment error of cable reflector [18]. Tanaka and Natori proposed a force density approximation for nonlinear static deformation and improved the shape and performance of the reflector numerically [19] [20]. Yali Zong et al. studied the analytical sensitivity analysis method of shape accuracy of uncertain parameters and cable tension [21]. 
For the shape control of the reflector antenna, there have been important topics of study in the literature for many years. Some researchers control the shape of the reflector surface by adjusting the actuators. For example, Anshul Sharma et al. studied the active vibration control of a piezoelectric ceramic reflector over wide temperature range [7]. Rajeev Kumar et al. applied the corresponding voltage to the piezoelectric actuators in the appropriate positions [22]. Optimizing actuation values of a set of actuators [23] and the electric potential of the orthotropic PZT actuators [24] have also been proposed. F. J. Peng et al. adjusted the temperature of memory alloy actuator as quickly as possible to achieve very good accuracy and tracking expectation [25]. Recently, Lili Tian et al. proposed a comprehensive design method for structural control of large deployable antenna panel electromechanical adjustment system [26]. Prior works in this area can be divided into two main categories: surface accuracy measurement and the shape control of reflector antennas. However, the above work is aimed at the control and optimization of surface accuracy, but not targeted at the electrical performance.

When the antenna deployed in orbit, the external thermal environment is complicated. The thermal distortion of the structure causes a sharp drop in the electrical performance of the antenna. For this situation, a control system of thermal distortion based on multipoint displacement adjustment technology is adopted. The system consists of a rigid structure, a plurality of actuators and an antenna reflector surface. The basic principle is that a plurality of actuators are mounted on the rigid structure and the antenna reflector surface is mounted on the actuators. According to the real-time deformation in orbit, the actuator produces a displacement opposite to the direction of thermal distortion.

This paper presents a method to adjust the values of expansion and contraction of actuators between the panel and supporting truss, so that the thermally induced shape distortion of reflector antenna can be counteracted accordingly, and then improve the electrical performance. Under the premise of considering the influence of temperature, different optimization objective models are established and the Particle Swarm Optimization (PSO) algorithm is used to solve the models. PSO is used to optimize the adjustments of actuators, which is firstly proposed by Kenndey and Eberhart [27]. Then, based on a finite element model of $5 \mathrm{~m}$ diameter reflector antenna, the process of adjusting actuators is simulated. After optimization, a set of values can be obtained, which makes the panel have a higher electrical performance after applying the temperature load. The numerical results show that the optimization method is more likely to improve the electrical performance.

The paper is organized as follows: Section 2 introduces the material and structure of the deployable reflector antenna, and analyzes the worst case of antenna when only the temperature load is applied. Section 3 describes the theory of optimization and the optimization model is established. The optimization objective functions and simulation results of the study are presented in Section 4, then Section 5 concludes the paper. 


\section{Modeling and Analysis}

The materials and parameters of the $5 \mathrm{~m}$ diameter deployable antenna are described in [26]. The folding scheme is needed to be used for the deployable reflector antenna in space, and the schematic diagram of the deployable antenna is shown in Figure 1. The reflector panels are connected to the support truss by 53 actuators, and full constraints are applied at the four corner joints of the center circle and the retainer plate. The other support points are constrained in the $\mathrm{x}$ and $y$ directions. The support truss and the distribution of actuators are shown in Figure 2.

The finite element model of the reflector antenna built with a triangular element is shown in Figure 3. On the premise of satisfying the efficiency of the main beam, the antenna size should be contracted as much as possible to meet the emission requirements. The dimension of the panel is shown in Figure 4.

\subsection{Worst Case Analysis of Antenna Structure}

In order to simulate the working conditions of the antenna in space and compensate the electrical performance, the paper firstly analyzes the structural deformation, RMS and far field radiation patterns in various cases, and finds out the worst case during the antenna operating.
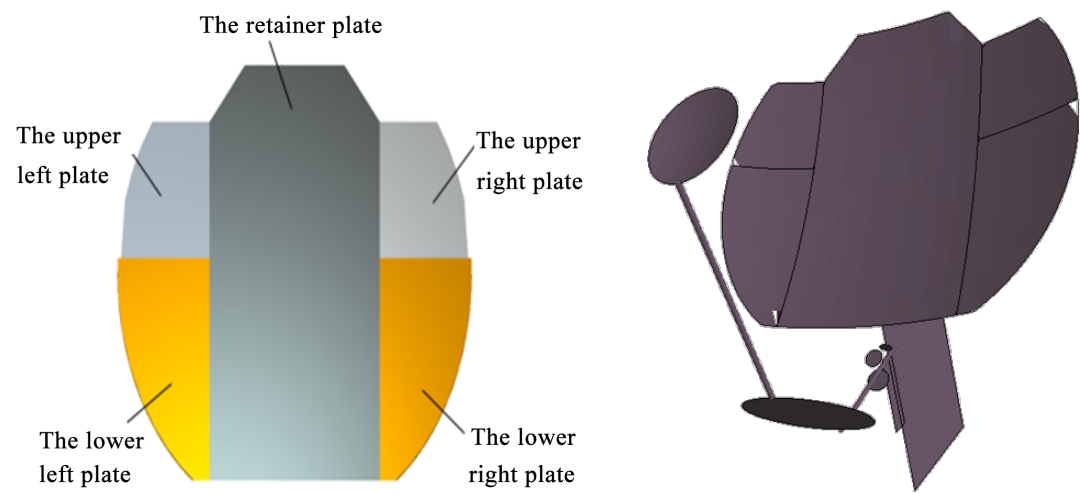

Figure 1. Schematic diagram of the deployable antenna.

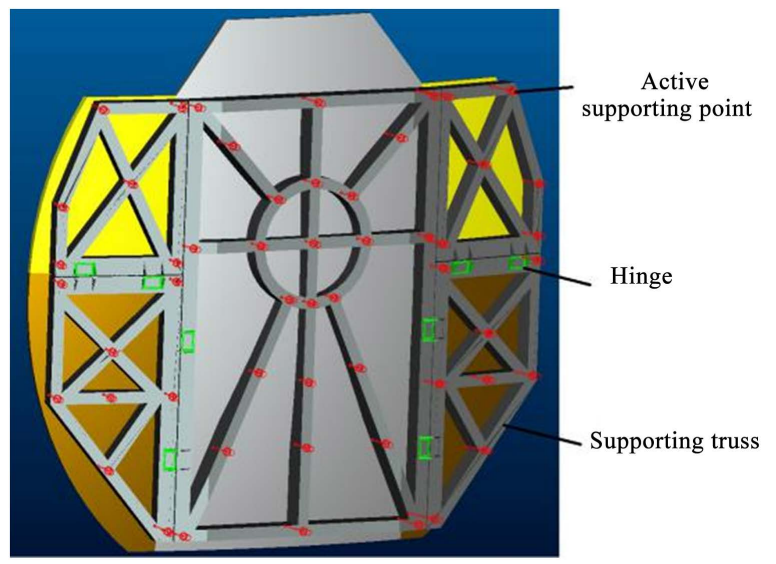

Figure 2. The support truss and distribution of actuators. 


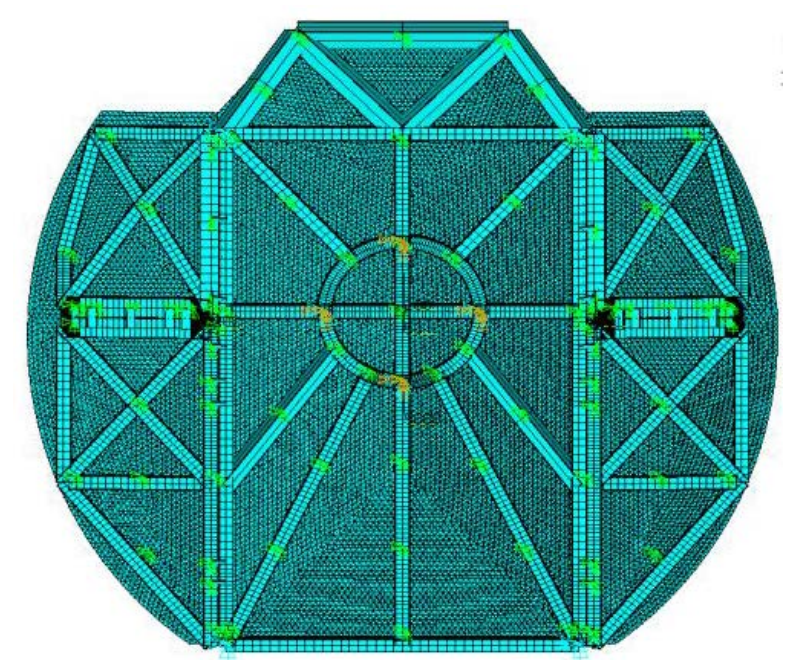

Figure 3. Finite element model.

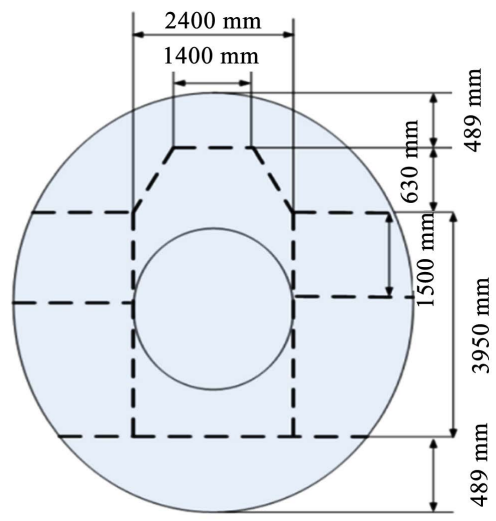

Figure 4. The specific cutting dimension.

This section compares the deformation of reflector antenna under uniform temperature loads with $-180^{\circ} \mathrm{C},-120^{\circ} \mathrm{C},-60^{\circ} \mathrm{C}, 0^{\circ} \mathrm{C}, 30^{\circ} \mathrm{C}, 90^{\circ} \mathrm{C}, 150^{\circ} \mathrm{C}, 200^{\circ} \mathrm{C}$ and different uneven temperature loads, respectively, the reference temperature is $20^{\circ} \mathrm{C}$. The deformation contours in $\mathrm{z}$-direction under uniform temperature loads and uneven temperature loads are shown in Figure 5 and Figure 6. And the thermal strain strength under uneven temperature loads are shown in Figure 7. Figure 8 shows the RMS curves in $\mathrm{x}, \mathrm{y}, \mathrm{z}$ directions under uniform temperature loads and the vector RMS in different cases.

The structural deformation of the reflector antenna is obtained by using FEM (finite element method). From the Figures 5-7, it can be seen that when the temperature load is $-180^{\circ} \mathrm{C}$, the deformation is the largest and the maximum value is $-0.6196 \mathrm{~mm}$. It can also be seen from the trend of RMS curves in Figure 8 when the different uniform temperature loads are applied, the root mean square in the $\mathrm{x}$-direction, $y$-direction, $z$-direction (RMS_x, RMS_y, RMS_z) is the maximum at $-180^{\circ} \mathrm{C}$, and when the uneven temperature loads and the uniform temperature loads are applied, the vector RMS (RMS_v) is the maximum at the uniform temperature load of $-180^{\circ} \mathrm{C}$ with the maximum value of 0.24 . 


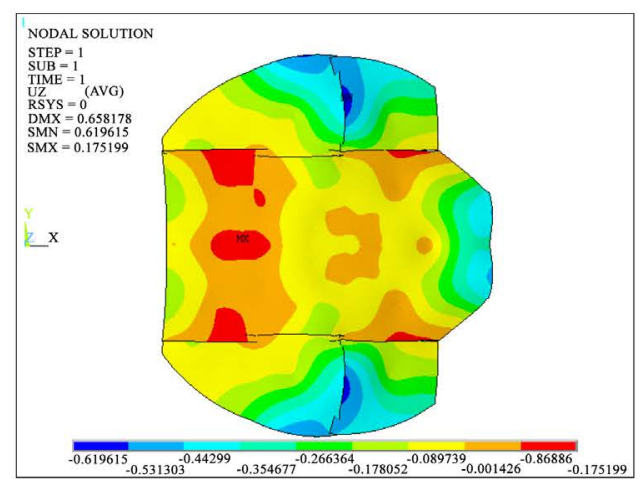

(a)

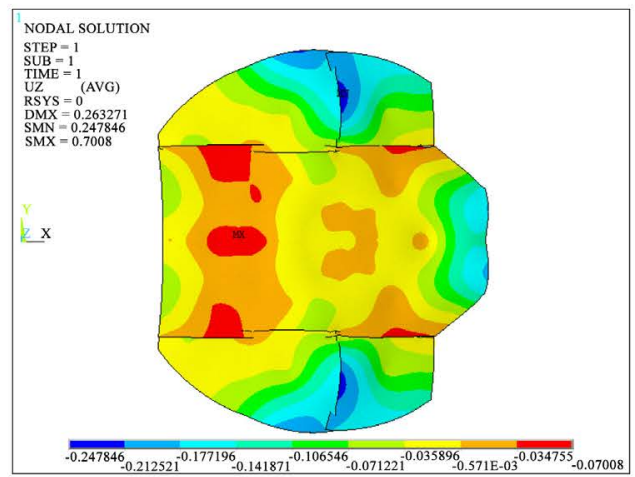

(c)

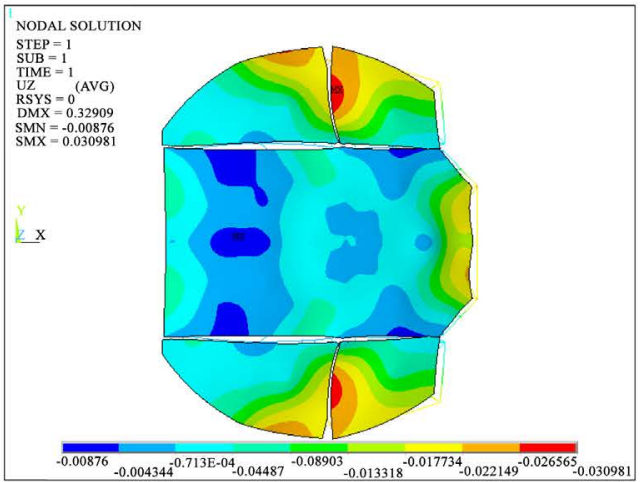

(e)

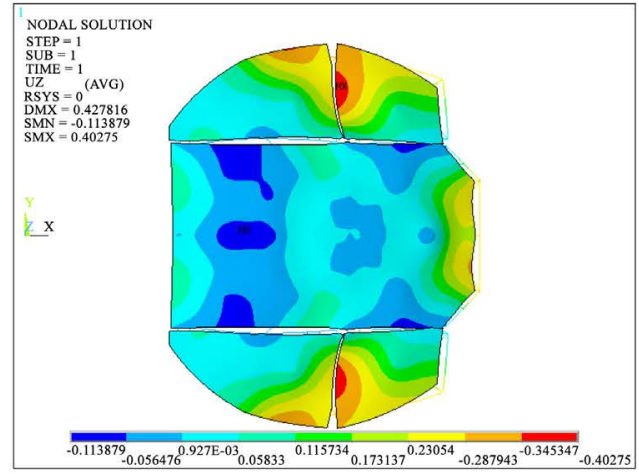

(g)

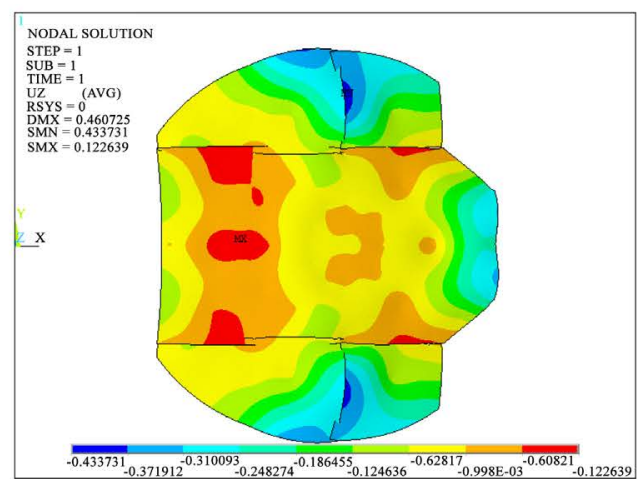

(b)

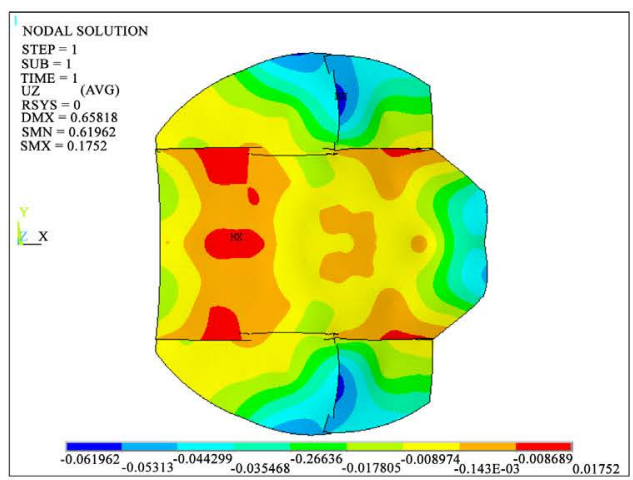

(d)

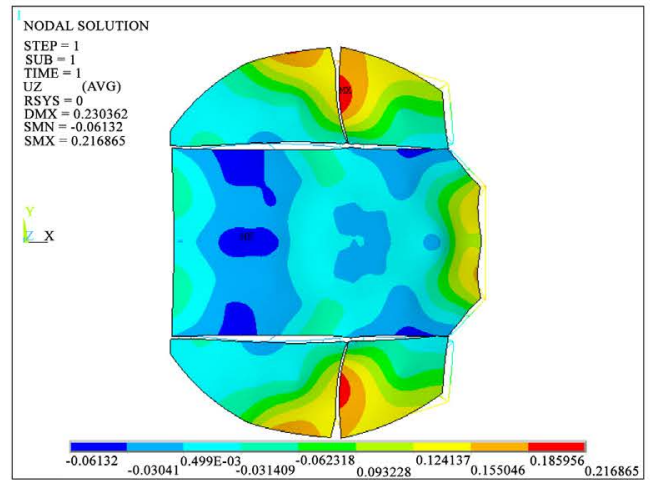

(f)

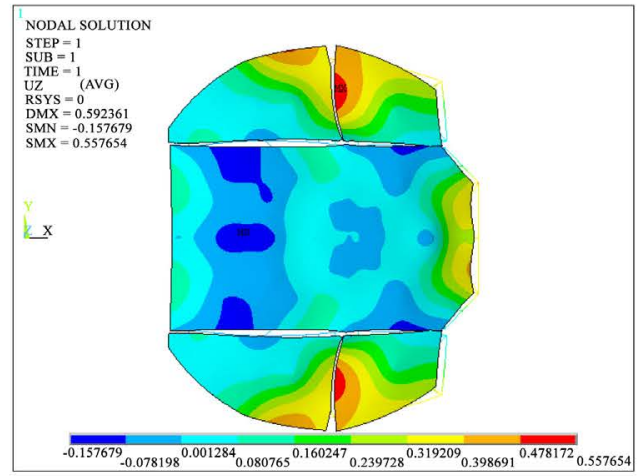

(h)

Figure 5. Uniform temperature load. (a) $\mathrm{T}=-180^{\circ} \mathrm{C}$, (b) $\mathrm{T}=-120^{\circ} \mathrm{C}$, (c) $\mathrm{T}=-60^{\circ} \mathrm{C}$, (d) $\mathrm{T}=0{ }^{\circ} \mathrm{C},(\mathrm{e}) \mathrm{T}=30^{\circ} \mathrm{C},(\mathrm{f}) \mathrm{T}=90^{\circ} \mathrm{C},(\mathrm{g})$ $\mathrm{T}=150^{\circ} \mathrm{C}$, (h) $\mathrm{T}=200^{\circ} \mathrm{C}$. 


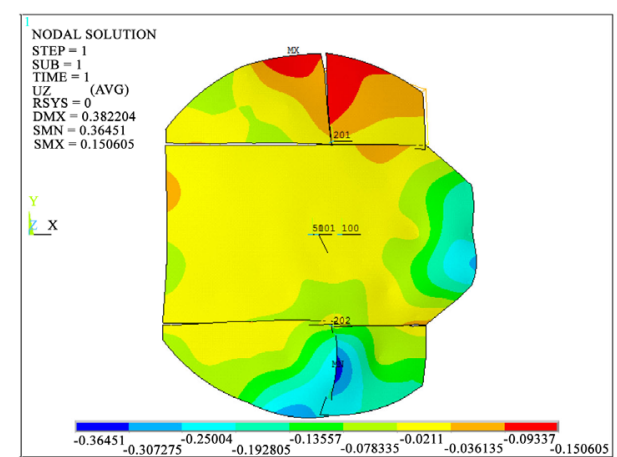

(a)

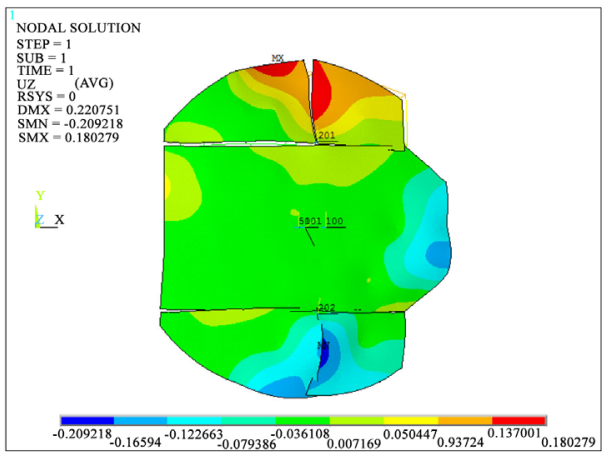

(c)

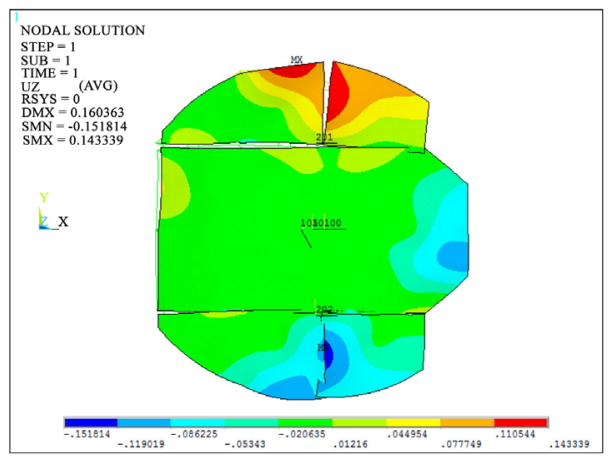

(b)

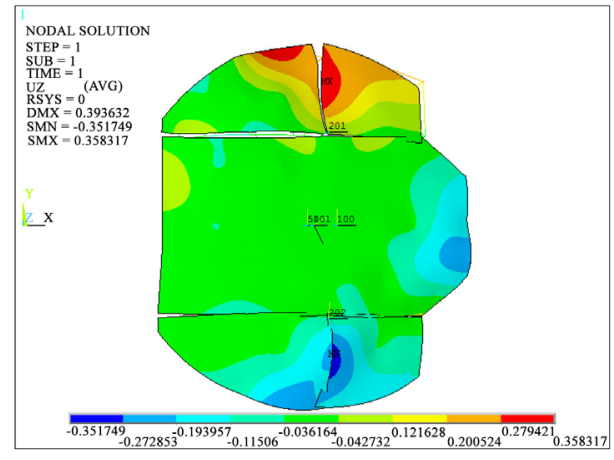

(d)

Figure 6. Uneven temperature load. (a) $\mathrm{T}=110^{\circ} \mathrm{C}--160^{\circ} \mathrm{C}$, (b) $\mathrm{T}=93^{\circ} \mathrm{C}--65^{\circ} \mathrm{C}$, (c) $\mathrm{T}=113^{\circ} \mathrm{C}--95^{\circ} \mathrm{C},(\mathrm{d}) \mathrm{T}=200^{\circ} \mathrm{C}--180^{\circ} \mathrm{C}$.

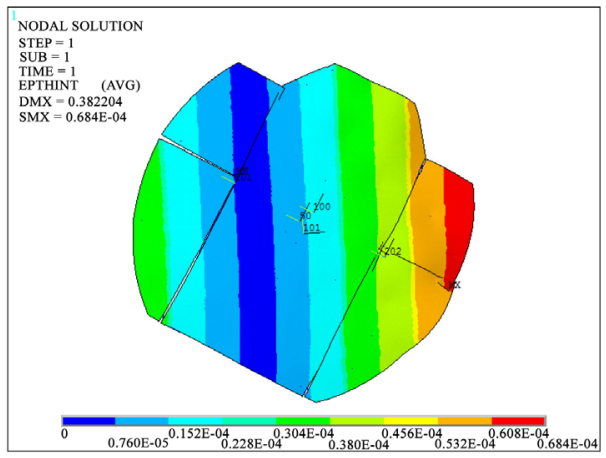

(a)

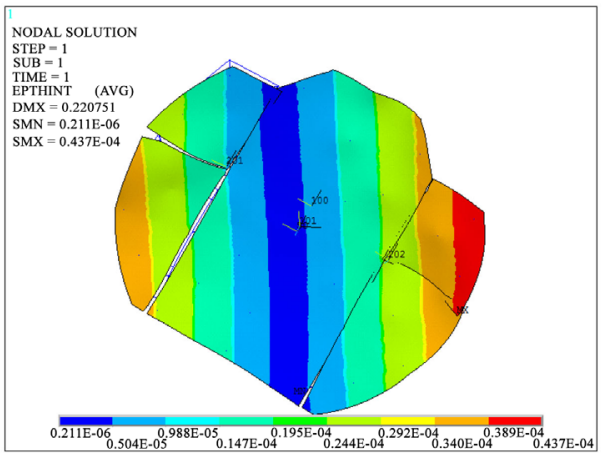

(c)

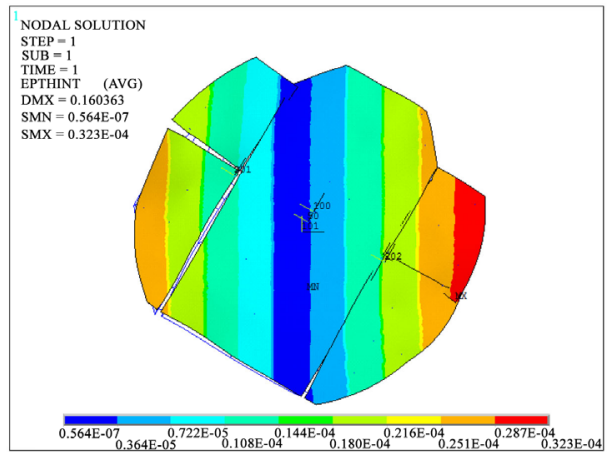

(b)

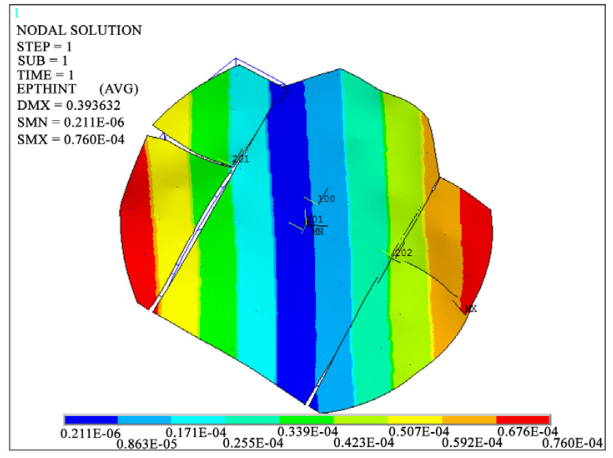

(d)

Figure 7. Thermal strain intensity under uneven temperature load. (a) $\mathrm{T}=110^{\circ} \mathrm{C}--160^{\circ} \mathrm{C}$, (b) $\mathrm{T}=93^{\circ} \mathrm{C}--65^{\circ} \mathrm{C},(\mathrm{c}) \mathrm{T}=113^{\circ} \mathrm{C}-$ $-95^{\circ} \mathrm{C},(\mathrm{d}) \mathrm{T}=200^{\circ} \mathrm{C}--180^{\circ} \mathrm{C}$. 


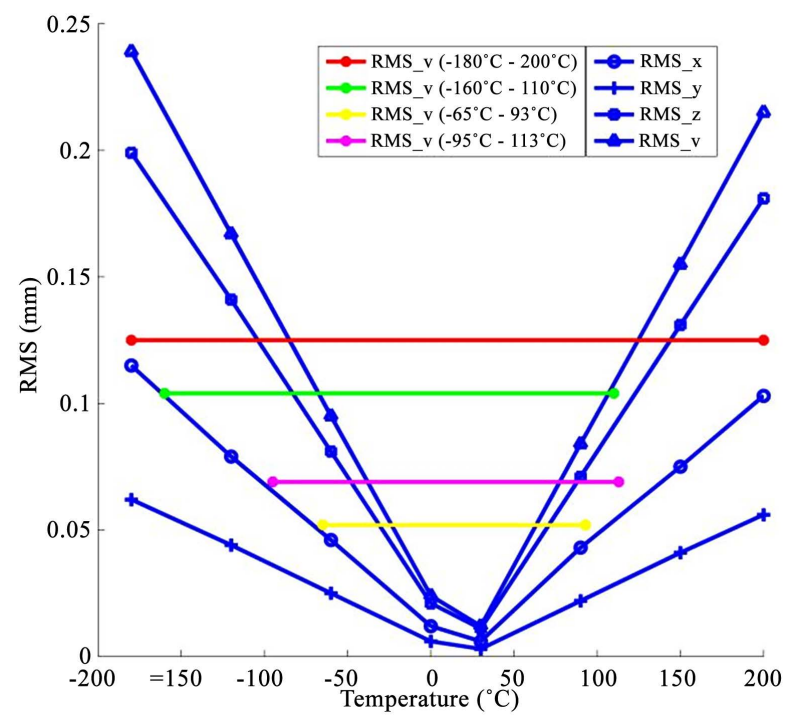

Figure 8. Comparison of RMS.

Therefore, we can obtain that the temperature load of $-180^{\circ} \mathrm{C}$ is the worst case of the structure of antenna.

\subsection{Analysis of Electrical Performance at the Worst Case}

The relationship between structural deformation and electrical performance of the antenna can be described as the electromechanical coupling model. The structure of the reflector antenna deformed under the temperature load. Then the deformation of the reflector can be transformed into the change of electromagnetic wave propagation distance, and the far field pattern can be calculated by converting into the phase error. The phase error on aperture surface is expressed as

$$
\phi_{s}(\delta(\beta))=\frac{4 \pi}{\lambda} \Delta z_{s}(\delta(\beta)) \cos ^{2}(\xi / 2)
$$

where $\lambda$ is the wavelength; $\Delta z$ is the error of reflector surface; $\xi$ is the angle of pitch; $\delta(\beta)$ is the structural deformation of antenna under temperature loads.

Introducing the phase error into the analysis model of electromagnetic field, the mathematical model of electromechanical coupling of the reflector antenna can be obtained [28] [29]

$$
\begin{aligned}
E(\theta, \varphi)= & \iint_{A} E_{0}\left(\rho^{\prime}, \varphi^{\prime}\right) \cdot \exp j\left[k \rho^{\prime} \sin \theta \cos \left(\varphi-\varphi^{\prime}\right)\right] \\
& \cdot \exp j\left[\phi_{s}(\delta(\beta))\right] \rho^{\prime} \mathrm{d} \rho^{\prime} \mathrm{d} \varphi^{\prime}
\end{aligned}
$$

where $(\theta, \varphi)$ is the observation direction in far field; $E_{0}\left(\rho^{\prime}, \theta^{\prime}\right)$ is the field distribution function on aperture surface.

According to the electromechanical coupling formula above, the worst working case of the electrical performance of $5 \mathrm{~m}$ diameter antenna is analyzed. The antenna works at $23.8 \mathrm{GHz}$ with Gaussian feed. The far field patterns of the an- 
tenna under different temperature loads are calculated and compared. Figure 9 shows the comparison of the ideal pattern and the far field patterns with uniform temperature loads of $-180^{\circ} \mathrm{C},-120^{\circ} \mathrm{C},-60^{\circ} \mathrm{C}, 0^{\circ} \mathrm{C}, 30^{\circ} \mathrm{C}, 90^{\circ} \mathrm{C}, 150^{\circ} \mathrm{C}$ and $200^{\circ} \mathrm{C}$. Figure 10 shows the comparison of the ideal pattern and the far field patterns with temperature loads of $-180^{\circ} \mathrm{C}, 200^{\circ} \mathrm{C}$ and uneven temperature loads of $-65-93^{\circ} \mathrm{C},-95-113^{\circ} \mathrm{C},-160-110^{\circ} \mathrm{C}$ and $-180-200^{\circ} \mathrm{C}$.

It can be seen from Figure 9 and Figure 10, the differences between the patterns at $-180^{\circ} \mathrm{C}$ and $200^{\circ} \mathrm{C}$ and the ideal pattern are biggest in all patterns, so it is only necessary to compare the electrical performance between these two conditions. The comparison between the left and right side lobe level of the ideal pattern and the far field pattern at $-180^{\circ} \mathrm{C}$ and $200^{\circ} \mathrm{C}$ are listed in Table 1.

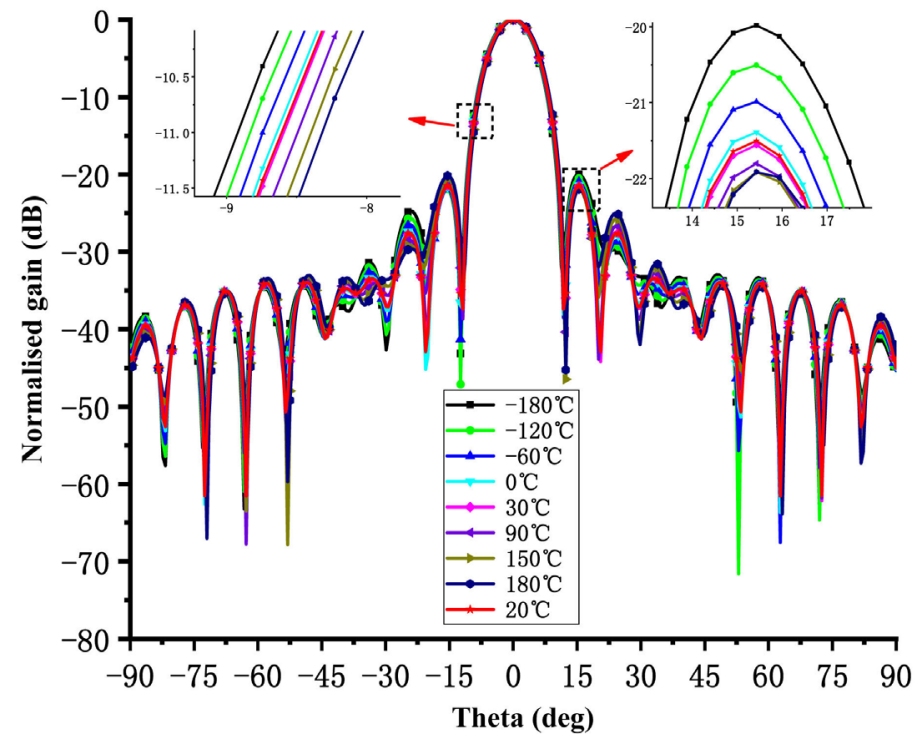

Figure 9. Comparison of patterns under uniform temperature load.

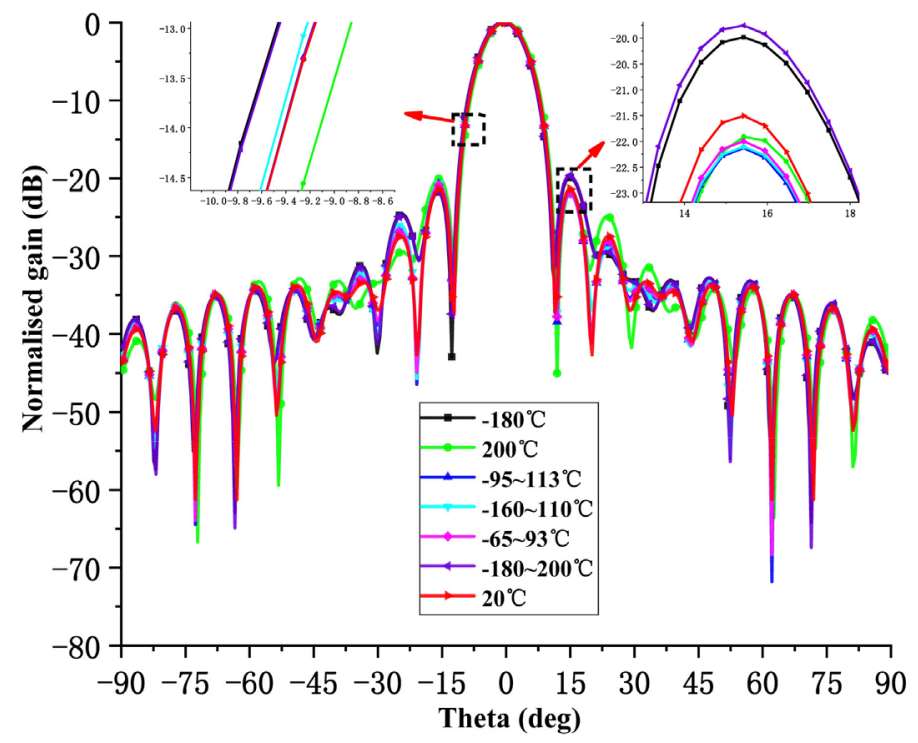

Figure 10. Comparison of patterns under uneven temperature load. 
Table 1. The comparison of side lobe levels.

\begin{tabular}{ccccc}
\hline $\begin{array}{c}\text { Temperature } \\
\left({ }^{\circ} \mathrm{C}\right)\end{array}$ & $\begin{array}{c}S L_{-} l \\
(\mathrm{~dB})\end{array}$ & $\begin{array}{c}\text { Difference with } \\
S L L_{-} i(\mathrm{~dB})\end{array}$ & $\begin{array}{c}S L L_{-} r \\
(\mathrm{~dB})\end{array}$ & $\begin{array}{c}\text { Difference with } \\
S L L_{-} i(\mathrm{~dB})\end{array}$ \\
\hline Ideal & -21.50 & 0 & -21.50 & 0 \\
-180 & -21.92 & -0.42 & -20.51 & +1.01 \\
200 & -20.16 & +1.34 & -21.91 & -0.41 \\
\hline
\end{tabular}

Note: "-" means lower than the $S L L_{-} i$; "+" means higher than the $S L L_{-} i$ in the third and fifth column; $S L L_{-} i$ means the side lobe level of the ideal far-field pattern; $S L L_{-} I$ means the left side lobe level of the objective far-field pattern; $S L L_{-} r$ means the right side lobe level of the objective far-field pattern.

From the pictures above, we can see that the difference between $S L L_{-} I$ and $S L L_{-} i$ is -0.42 at temperature load of $-180^{\circ} \mathrm{C}$ and 1.34 at temperature load of $200^{\circ} \mathrm{C}$. the difference between $S L L_{-} r$ and $S L L_{-} i$ is 1.01 at temperature load of $-180^{\circ} \mathrm{C}$ and -0.41 at temperature load of $200^{\circ} \mathrm{C}$. So $200^{\circ} \mathrm{C}$ is the worst case of the electrical performance and $-180^{\circ} \mathrm{C}$ is the worst case of the structure. Since the difference is not big, the following work is performed on the basis of $-180^{\circ} \mathrm{C}$.

\section{Optimization Theory}

In order to compensate the influence of thermal distortion, an optimization model is established to calculate the optimal adjustments. Firstly, based on the configuration parameters, the finite element model is built with temperature loads. Giving a group of adjustments to the actuator as displacement constraints, the structural deformation $\delta(\beta)$ in Equation (1) can be derived, and then the phase error on aperture surface of the antenna is obtained. Secondly, according to the electromechanical coupling formula as Equation (2), the far field radiation pattern is derived. Comparing with the ideal radiation pattern, if the optimized far-field electric field value approach to the ideal far-field electric field value, which means the objective function is satisfied. Then the iteration stops, or into the next step. The PSO algorithm is used to solve the optimization model. The flow chart is shown in Figure 11. The blue line represents the flow chart of solving the $E_{1}$ of the far field electric field value of the antenna without applying the temperature load, and the red line represents the flow chart of solving the $E_{2}$ of the far field electric field value of the antenna after applying the temperature load and optimizing the adjustment of the actuators.

$E_{1}$ represents the far-field radiation electric field value under the ideal condition, $E_{2}$ represents the far-field radiation electric field value of the antenna optimized after applying temperature load. The formulas for calculating the $E_{1}$ and $E_{2}$ of the far field electric field are as follows:

$$
E=-\frac{j \omega \mu_{0}}{2 \pi r} \mathrm{e}^{-j k r}\left[\sqrt{\frac{\varepsilon_{0}}{\mu_{0}}} \frac{P_{t}}{4 \pi}\right] \int_{0}^{2 \pi} \int_{0}^{d / 2} \frac{\sqrt{G_{f}\left(\xi, \phi^{\prime}\right)}}{r^{\prime}} \cdot \mathrm{e}^{j k \rho \sin \theta \cos \left(\phi-\phi^{\prime}\right)} \rho \mathrm{d} \rho \mathrm{d} \phi^{\prime}
$$

where $\sqrt{G_{f}\left(\xi, \phi^{\prime}\right)}$ is the feed direction function; $P_{t}$ is the total radiation power of feed. 


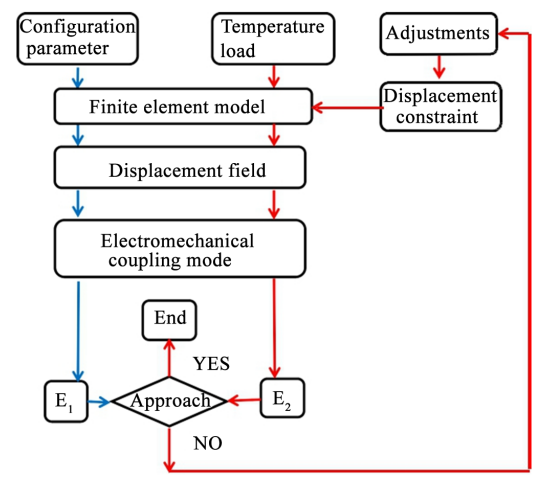

Figure 11. Flow chart.

\subsection{Deformation of a Single Panel}

For a single reflector panel, such as the upper left panel in Figure 1. The finite element model is shown in Figure 12. Actuators are distributed at the six points of the panel shown as Figure 13. Adjusting these six actuators means that displacement constraints are applied at the six nodes respectively. Then the deformation of each node on the single panel can be obtained by static structure analysis. Obviously, there are different deformations under different adjustments.

For example, the normal displacement of $15,-15,15,-15,15$, and $-15 \mathrm{~mm}$ is applied at nodes $517,518,519,520,521,522$, respectively, and the full constraints are applied at nodes 530 and 531, shown in Figure 13. Then the coordinate and deformation information of each node on the panel is obtained by the finite element analysis. The displacement contour is shown in Figure 14 and the stress contour is shown in Figure 15.

The same method can also be used to other panels of reflector antenna. The deformation of the panel can be obtained by applying different normal displacements to the actuators. Then the displacement information of each node on the panel is derived by using the finite element analysis, therefore the structural displacement field can be obtained. According to electromechanical coupling model in Section 2.2, the far field radiation pattern is obtained.

\subsection{The Optimization Model}

Based on the deformation of a single panel, the shape accuracy of whole reflector surface can be controlled by adjusting all actuators. In order to compensate the influence of thermal distortion on electrical performance, a group of optimal adjustments for all actuators should be calculated. Therefore an optimization model is established as

$$
\left\{\begin{array}{l}
\text { Find : } \boldsymbol{X}=\left(x_{1}, x_{2}, \cdots, x_{i}, \cdots, x_{n}\right)^{\mathrm{T}} \\
\min : f(\boldsymbol{X}) \\
\text { s.t. }:-x_{\max } \leq x_{i} \leq x_{\max } \\
\quad \sigma_{\max } \leq[\sigma] \\
\quad-\theta_{i} \leq \theta \leq \theta_{i}
\end{array}\right.
$$




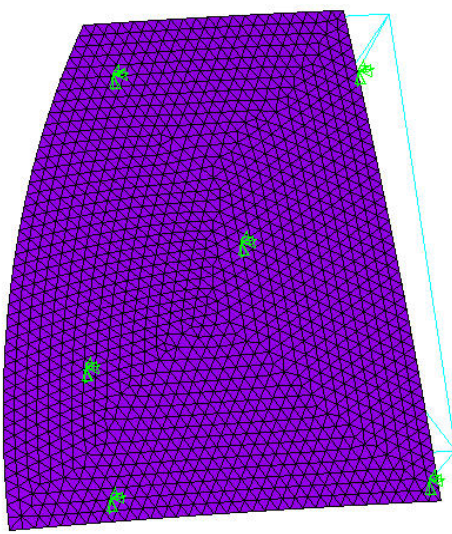

Figure 12. The finite element model.

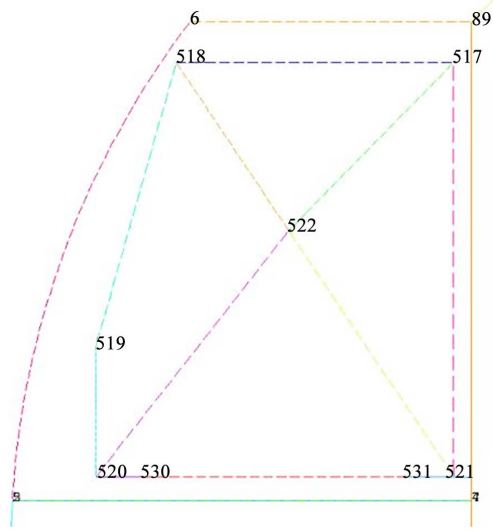

Figure 13. The positions of points.
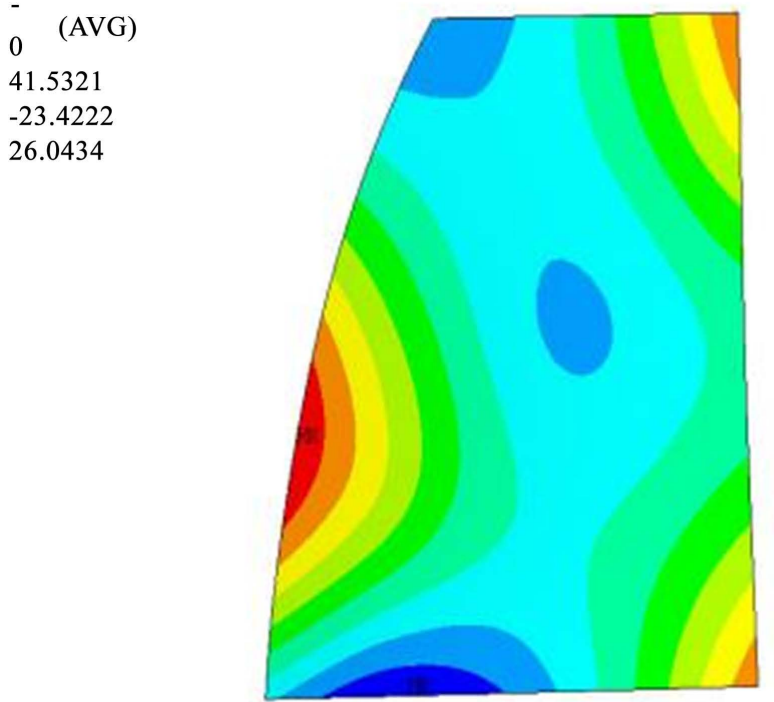

$-23.422-17.9261^{-12.4299}-6.93369^{-1.43752} 4.05866^{9.55484} 15.0511^{20.5472} 26.0434$

Figure 14. Displacement contour. 


\section{(AVG)}

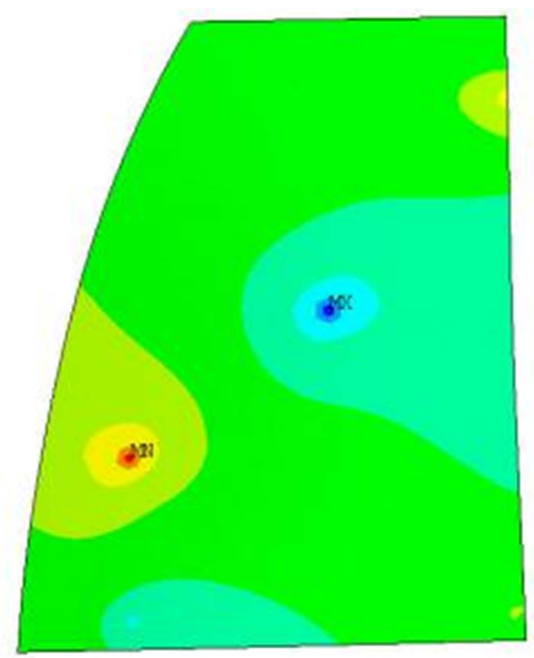

Figure 15. Stress contour.

where $X=\left(x_{1}, x_{2}, \cdots, x_{i}, \cdots, x_{n}\right)$ represents the value of adjustments of $\mathrm{n}$ actuators'; $f(X)$ is the objective function; $x_{\max }$ is the maximum value of adjustment; $[\sigma]$ is the allowable stress. The constraints are the maximum stroke and the minimum stroke of the actuators; the stresses of the actuators should be less than their allowable stresses and $\theta$ represents the interval of optimization. For the optimization model established above, the particle swarm optimization (PSO) algorithm is used to solve it.

\section{Numerical Simulations}

\section{Comparison of Different Objective Functions}

Since the deformation of the panel affects the structural accuracy of the antenna and influences the electrical performance, the PSO algorithm is used to optimize the adjustments of the actuators, which compensates the degradation of electrical performance due to thermal distortion.

In order to achieve different goals, several different optimization objective functions are established. Different objective functions and their corresponding iterative curves are shown in Table 2. where $f_{1}(X)=-\left[\left(S L L_{-} l\right)^{2}+\left(S L L_{-} r\right)^{2}\right]$ represents the sum of squares of the left and right side lobe of the objective far field radiation pattern;

$f_{2}(\boldsymbol{X})=\left(S L L_{-} l-S L L_{-} i\right)^{2}+\left(S L L_{-} r-S L L_{-} i\right)^{2}$ represents the sum of squares of the difference between the left and right side lobes of the ideal far field radiation pattern and the objective far field radiation pattern;

$$
\begin{aligned}
& f_{3}(\boldsymbol{X})=\operatorname{sqrt}\left(\operatorname{sum}\left((\Delta E-\text { mean }(\Delta E))^{2}\right) / m\right) \text { and } \\
& f_{4}(\boldsymbol{X})=\operatorname{sqrt}\left(\operatorname{sum}\left((\Delta E-\text { mean }(\Delta E))^{2}\right) / m\right) \text { are used to make the objective }
\end{aligned}
$$


Table 2. Comparison of different objective functions and iterative curves.

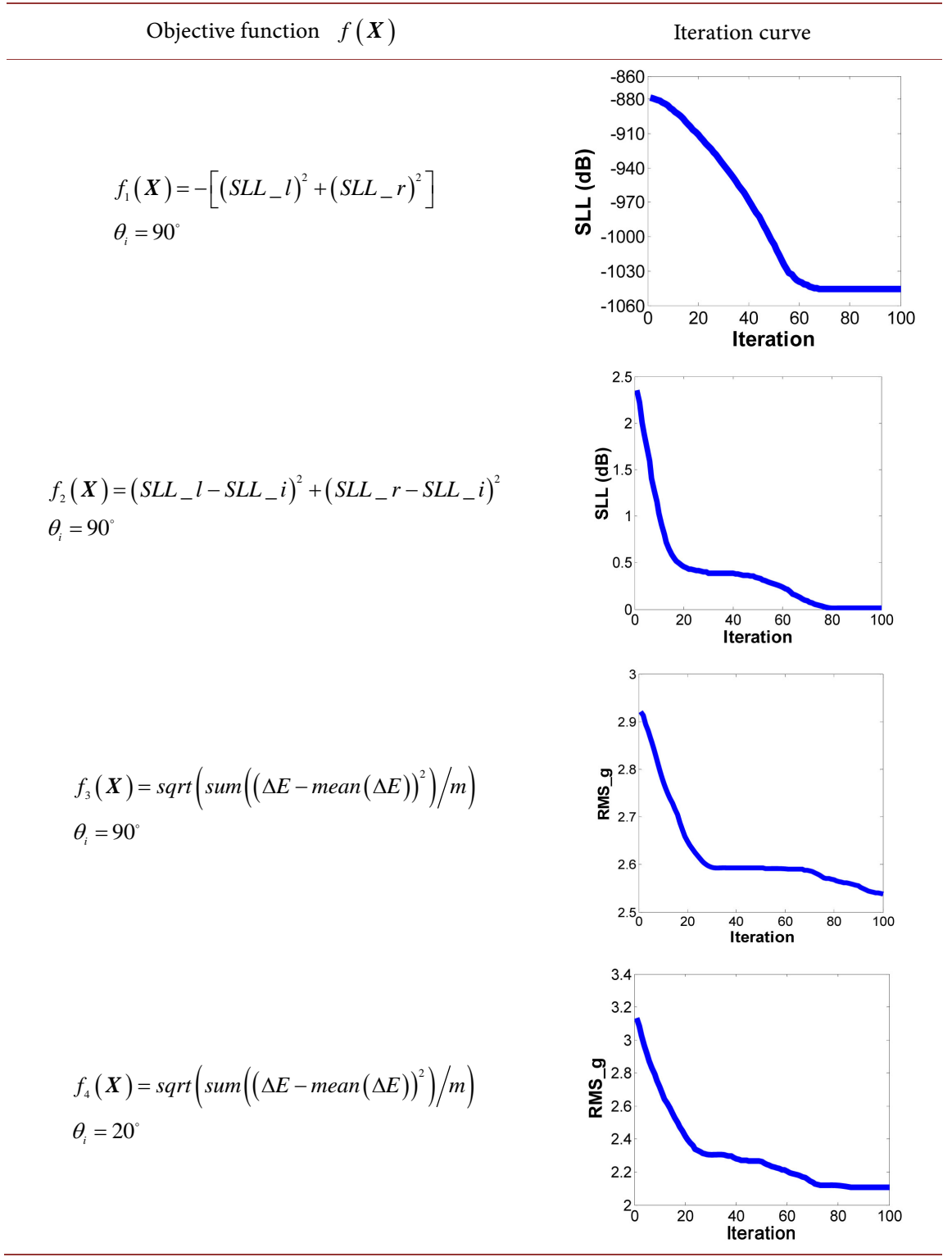

pattern of the deformed reflector antenna optimally approximate to the ideal pattern, the angle of $f_{3}$ is from -90 degrees to 90 degrees, and the angle of $f_{4}$ is from -20 degrees to 20 degrees, which makes the pattern approximate partially. And $\Delta E=E_{1}-E_{2}$ represents the difference between the objective pattern and the ideal pattern; mean $(\Delta E)$ means the mean value of the difference between the objective pattern and the ideal pattern; $m$ means the discrete number points of the far field pattern.

Patterns of different objective functions at e-plane are shown in Figure 16. And the data under different objective functions are shown in Table 3. It can be concluded: the side lobes of the second objective are closest to the side lobes of the ideal pattern in Figure 16. And the difference between $S L L_{-} l$ and $S L L_{-} i$ is 0.01 , and the difference between $S L L \_r$ and $S L L \_i$ is 0.02 , which are the smallest. 


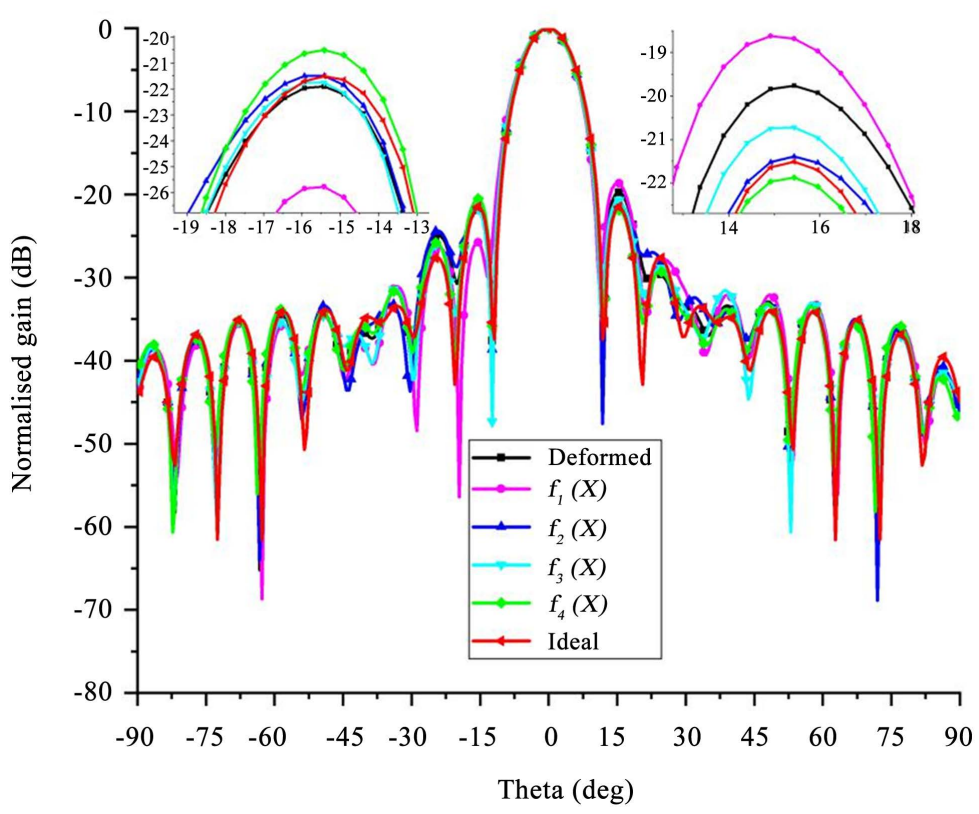

Figure 16. Patterns of different objective functions at e-plane.

Table 3. Parameters under different objective functions.

\begin{tabular}{cccccc}
\hline $\begin{array}{c}\text { Temperature } \\
\left(-180^{\circ} \mathrm{C}\right)\end{array}$ & $\begin{array}{c}S L_{-} l \\
(\mathrm{~dB})\end{array}$ & $\begin{array}{c}\text { Difference } \\
\text { with } S L_{-} i(\mathrm{~dB})\end{array}$ & $\begin{array}{c}S L_{-} r \\
(\mathrm{~dB})\end{array}$ & $\begin{array}{c}\text { Difference } \\
\text { with } S L_{-} i(\mathrm{~dB})\end{array}$ & $\begin{array}{c}\text { RMS } \\
(\mathrm{mm})\end{array}$ \\
\hline Ideal & -21.50 & $/$ & -21.50 & $/$ & 0 \\
Deformed & -21.92 & -0.42 & -20.51 & +1.00 & 0.199 \\
The first objective & -24.36 & -2.86 & -19.46 & +2.04 & 0.280 \\
The second objective & -21.49 & +0.01 & -21.48 & +0.02 & 0.216 \\
The third objective & -21.76 & -0.25 & -20.71 & +0.79 & 0.199 \\
The forth objective & -20.50 & +1.01 & -21.87 & -0.37 & 0.238 \\
\hline
\end{tabular}

And the RMS of reflector antenna is increased from 0.199 to 0.216 in the second objective.

These results show that the electrical performance of the second objective is the best. The RMS is also enlarged, which relaxes the structural accuracy and ensures the electrical performance.

\section{Conclusions}

In this paper, the method of optimizing the actuators' adjustments is used to compensate the thermal distortion for improving electrical performance of the antenna under temperature loads. It can be concluded that $-180^{\circ} \mathrm{C}$ is the worst working condition of the antenna by analyzing the RMS and electrical performance of the antenna under different temperature loads. On this basis, four different optimization objective functions are established according to different requirements, and the equations are solved by using the PSO algorithm. It can be seen from the results that the optimization results of the second objective func- 
tion are the best, the electrical performance is the best, and the structural accuracy is also relaxed.

The numerical results show that compared with the traditional electromechanical separation method, this method can improve the electrical performance of the reflector antenna and reduce the difficulty of engineering processing, which can be used as a reference for engineering practice. At the same time, as an active surface compensation technique, this method can also be used in large-scale ground reflector antenna engineering

When using optimization algorithm to solve electromechanical coupling optimization model, only the most classical PSO particle swarm optimization algorithm is used in this paper. In intelligent optimization algorithm, there are many optimization algorithms that can solve electromechanical coupling model. In the future, we will try to use different optimization algorithms to solve the optimization model to analyze and compare.

\section{Fund}

This work was supported in part by the National Natural Science Foundation of China under Grant 51490661.

\section{Conflicts of Interest}

The authors declare no conflicts of interest regarding the publication of this paper.

\section{References}

[1] Ding, J.H. and Tzou, H.S. (2004) Micro-Electromechanics of Sensor Patches on Free Paraboloidal Shell Structronic Systems. Mechanical Systems and Signal Processing, 18, 367-380. https://doi.org/10.1016/S0888-3270(02)00222-4

[2] Meguro A, Shintate K, Usui, M. and Tsujihata A. (2009) In-Orbit Deployment Characteristics of Large Deployable Antenna Reflector Onboard Engineering Test Satellite VIII. Acta Astronautica, 65, 1306-1316. https://doi.org/10.1016/j.actaastro.2009.03.052

[3] Zhang, S., Duan, B., Yang, G., Zong, Y. and Zhang, Y. (2013) An Approximation of Pattern Analysis for Distorted Reflector Antennas Using Structural-Electromagnetic Coupling Model. IEEE Transactions on Antennas and Propagation, 61, 4844-4847. https://doi.org/10.1109/TAP.2013.2267200

[4] Agrawal, B.N., Elshafei, A.A. and Song, G. (1997) Adaptive Antenna Shape Control Using Piezoelectric Actuators. Acta Astronautica, 40, 821-826. https://doi.org/10.1016/S0094-5765(97)00185-9

[5] Jha, A.K., Inman, D.J. and Raymond, H.P. (2002) Free Vibration Analysis of an Inflated Toroidal Shell. Journal of Vibration and Acoustics, 124, 387-396. https://doi.org/10.1115/1.1467650

[6] Michael, F, Inman D.I. and Rietz, R.W. (1997) Active Damping of Thermally Induce Vibrations. Journal of Intelligent Material Systems and Structures, 8, 678-685. https://doi.org/10.1177/1045389X9700800805

[7] Sharma, A., Kumar, R., Vaish, R. and Chauhan, V.S. (2015) Active Vibration Con- 
trol of Space Antenna Reflector over Wide Temperature Range. Composite Structure, 128, 291-304. https://doi.org/10.1016/j.compstruct.2015.03.062

[8] Iwasa, T., Ota, K., Harada, T. and Muramatsu, R. (2018) High-Resolution Surface Shape Measurement of Parabola Antenna Reflector by Using Grating Projection Method with Virtual Targets. Acta Astronautica, 153, 95-108.

https://doi.org/10.1016/j.actaastro.2018.09.031

[9] Shimizu, M. (1996) Study of Shape Control for Modular Mesh Antenna. Electronics and Communications in Japan (Part I: Communications), 79, 75-83. https://doi.org/10.1002/ecja.4410791208

[10] Feng, S., Duan, B., Wang, C., Ban, Y. and Wang, W. (2019) Novel Worst-Case Surface Accuracy Evaluation Method and Its Application in Reflector Antenna Structure Design. IEEE Access, 7, 140328-140335. https://doi.org/10.1109/ACCESS.2019.2943130

[11] Jenkins, C.H., Kalanovic, V.D., Padmanabhan, K. and Faisal, S.M. (1999) Intelligent Shape Control for Precision Membrane Antennae and Reflectors in Space. Smart Materials \& Structures, 8, Article No. 857. https://doi.org/10.1088/0964-1726/8/6/313

[12] Bouzidi, R. and Lecieux, Y. (2012) A Numerical Method to Optimize the Design of a Space Inflatable Membrane Reflector. Acta Astronautica, 74, 69-78. https://doi.org/10.1016/j.actaastro.2011.12.009

[13] San, B., Wu, Y. and Sun, X. (2014) Shape Error Study of Inflatable Antennas Using a Numerical Model. Acta Astronautica, 104, 11-25. https://doi.org/10.1016/j.actaastro.2014.07.018

[14] San, B., Yang, Q. and Yin, L. (2017) Stochastic and Sensitivity Analysis of Shape Error of Inflatable Antenna Reflectors. Acta Astronautica, 132, 170-176. https://doi.org/10.1016/j.actaastro.2016.12.015

[15] Liu, R., Guo, H., Liu, R., Wang, H., Tang, D. and Song, X. (2017) Shape Accuracy Optimization for Cable-Rib Tension Deployable Antenna Structure with Tensioned Cables. Acta Astronautica, 140, 66-77. https://doi.org/10.1016/j.actaastro.2017.07.047

[16] Liu, R., Guo, H., Liu, R., Wang, H., Tang, D. and Deng, Z. (2018) Structural Design and Optimization of Large Cable-Rib Tension Deployable Antenna Structure with Dynamic Constraint. Acta Astronautica, 151, 160-172. https://doi.org/10.1016/j.actaastro.2018.05.055

[17] Du, J., Bao, H. and Cui, C. (2014) Shape Adjustment of Cable Mesh Reflector Antennas Considering Modeling Uncertainties. Acta Astronautica, 97, 164-171. https://doi.org/10.1016/j.actaastro.2014.01.001

[18] Du, J., Gu, Y., Bao, H., Wang, C. and Chen, X. (2018) Shape Adjustment Optimization and Experiment of Cable-Membrane Reflectors. Acta Astronautica, 146, 192-201. https://doi.org/10.1016/j.actaastro.2018.02.037

[19] Tanaka, H. and Natori, M.C. (2004) Shape Control of Space Antennas Consisting of Cable Networks. Acta Astronaut, 55, 519-527. https://doi.org/10.1016/j.actaastro.2004.05.014

[20] Tanaka, H. and Natori, M.C. (2007) Shape Control of Cable-Network Structures Based on Concept of Self-Equilibrated Stresses. International Journal Series C Mechanical Systems, Machine Elements and Manufacturing, 49, 1067-1072. https://doi.org/10.1299/jsmec.49.1067

[21] Zong, Y., Hu, N., Duan, B., Yang, G., Cao, H. and Xu, W. (2016) Manufacturing Error Sensitivity Analysis and Optimal Design Method of Cable-Network Antenna 
Structures. Acta Astronautica, 120, 182-191.

https://doi.org/10.1016/j.actaastro.2015.11.026

[22] Kumar, R., Mishra, B.K. and Jain, S.C. (2005) Thermally Induced Shape Distortion Control of Antenna Reflector with Piezoelectric Patches. ISSS-2005/PS-19, 28-30 July 2005, Bangalore.

[23] Yoon, H.-S. and Washington, G. (2010) An Optimal Method of Shape Control for Deformable Structures with an Application to a Mechanically Reconfigurable Reflector Antenna. Smart Materials and Structures, 19, Article ID: 105004. https://doi.org/10.1088/0964-1726/19/10/105004

[24] Luo, Q. and Tong, L. (2006) High Precision Shape Control of Plates Using Orthotropic Piezoelectric Actuators. Finite Elements in Analysis and Design, 42, 1009-1020. https://doi.org/10.1016/j.finel.2006.03.002

[25] Peng, F., Jiang, X.X., Hu, Y.R. and Ng, A. (2008) Actuation Precision Control of SMA Actuators Used for Shape Control of Inflatable SAR Antenna. Acta Astronautica, 63, 578-585. https://doi.org/10.1016/j.actaastro.2008.01.043

[26] Lili, T., Hong, B., Meng, W. and Duan, X. (2016) Modeling and Control of the Redundant Parallel Adjustment Mechanism on a Deployable Antenna Panel. Sensors, 16, Article No. 1632. https://doi.org/10.3390/s16101632

[27] Shi, Y. and Eberhart, R.C. (1999) Empirical Study of Particle Swarm Optimization. Proceedings of the 1999 Congress on Evolutionary Computation-CEC99, Washington DC, 6-9 July 1999, 1945-1950. https://doi.org/10.1109/CEC.1999.785511

[28] Duan, B.Y. (2011) Theory, Methods and Applications on Electromechanical Coupling of Electronic Equipment. Science Press, Beijing.

[29] Duan, B.Y. (2002) Review of Antenna Structure Design with Mechatronics in China. Mechatronics, 12, 657-667. https://doi.org/10.1016/S0957-4158(01)00015-0 